\title{
Coalitions of reciprocity and the maintenance of financial integrity within informal value transmission systems: The operational dynamics of contemporary hawala networks
}

\section{Roger Ballard}

Centre for Applied South Asian Studies, University of Manchester, Manchester M13 9PL, UK tel/fax: + 44161 2753605; e-mail: r.ballard@man.ac.uk

Roger Ballard is an anthropologist by training. He has a long-standing interest in the ethnic colonies which south Asian labour migrants have constructed since their arrival in the UK, as well as in the transnational networks which those involved have developed to facilitate the circulation of personnel, ideas and material resources on a global scale. The arguments and analyses presented in this paper are a product of his long-standing interest in migration and its consequences, as well as his experience of acting as an expert witness in legal proceedings.

\section{Abstract}

On a global scale, the estimated flow of migrant workers' remittances through formal channels now comfortably exceeds \$100bn per annum, while the unrecorded flow through informal channels amounts to at least as much again. During the last few years the Informal Value Transmission Systems (IVTS) networks through which the latter are transferred have attracted a great deal of attention, both because of a gradual realisation of their scale, and because of fears that they could provide a vehicle for drug smugglers and terrorists to shift funds without fear of detection by the authorities. Recently reinforced anti-money laundering ( $A M L / C F T)$ regulations aimed at curbing such illegitimate transfers are having an expensive impact on all sections of the financial services industry, no less in the formal than the informal sector. As yet, however, remarkably little attention has been paid to the basis on which the so-called 'underground' networks in the informal sector actually operate, the basis on which they organise and guarantee the security of their financial operations, let alone the extent to which they may have developed their own internal mechanisms for keeping drug smugglers and terrorist financiers at bay. In the same vein there is little awareness of the extent to which these 'informal' networks now use sophisticated communications technology, including Swift and telegraphic transfer (TT), to implement their transactions, and the extent to which the financial liquidity generated by remittances now plays a key role in supporting commercial counter-trade. Based on first-hand observations of the activities of Anglo-Pakistani hawala networks, this paper presents an empirically informed account of the operation of IVTS as highly efficient financial systems, and on this basis explores whether recently reinforced $A M L /$ CFT initiatives are fit for their purpose.
Journal of Banking Regulation, Vol. 6, No. 4,

2005, pp. 319-352

(C) Henry Stewart Publications, 


\section{INTRODUCTION}

As everyone even remotely involved in the global financial services sector is now well aware, the new set of regulatory obligations aimed at curbing money laundering with which compliance is now required is having a significant impact on business practices. Taking on new customers, receiving funds from them, and even implementing their existing customers' instructions is now a far less straightforward task than it once was. A vastly reinvigorated AML/CFT regime now requires the identity of customers and the source of any funds they may proffer to be checked out far more extensively than straightforward commercial prudence has always required. Not only must proof positive of their customers' identity and their business activities now be obtained as a matter of routine, but every organisation within the sector has now acquired a new duty: to monitor their customers' financial activities, and to report all potentially suspicious transactions reported to the authorities. Failure to take adequate steps to comply with these requirements can precipitate sanctions of considerable severity - not excluding the prospect of criminal prosecution. These requirements are currently being rolled out on a global basis, and are by no means solely restricted to banks: insurance companies, accountants, lawyers, stockbrokers, auction houses, estate agencies and many others must now meet the same requirements; recent estimates of the total cost of compliance to these requirements in the USA alone could amount to as much as $\$ 10.9$ bn per annum. ${ }^{1}$

While efforts to counter money laundering — itself a markedly ill-defined concept $^{2}$ - can be traced back to the days of prohibition, the current regulatory framework is largely the product of the activities of the Financial Crimes Enforcement Network (FinCEN). This transnational organisation was established by the
US Treasury in 1990, and its thinking appears to have inspired most of the financial provisions set out in the USA Patriot Act, a measure passed into law at great speed in the immediate aftermath of the events of 9/11. While FinCEN's initial agenda was primarily directed at disrupting the activities of drug smugglers, the USA Patriot Act had much broader concerns. As its full title - Uniting and Strengthening America by Providing Appropriate Tools Required to Intercept and Obstruct Terrorism - makes abundantly clear, terrorist finance no less than drug smuggling is now the principal driving force behind the reinforced antimoney laundering initiatives to which the Act gave rise. Nor have these initiatives been limited to the USA. Since the Act came into force the US Government placed the full weight of its diplomatic resources behind efforts to persuade all other countries to introduce similar regulatory regimes, while the Act's provisions giving the US authorities powers to impound the US-based assets of any overseas institu-tion deemed to have fallen foul of its expectations added further financial muscle to the whole operation. Given the dollar's role as the global medium of exchange, and New York's role as the ultimate financial hub for all such exchanges, no serious player in the global economic arena can now afford to ignore the provisions of the Act. ${ }^{3}$

As result of its efforts to build a sanitising wall around the US dollar-based financial transactions, these provisions brought an ill-understood sphere of global financial activity - the informal 'swap' arrangements which are commonly described as 'underground banking' - into much more dramatic focus. Given that such arrangements enabled huge financial deals to be completed largely outwith the bounds of the formally constituted financial sector, and in such a way that they left no audit 
trails which could subsequently be subjected to regulatory scrutiny, alarm bells began to ring ever more loudly. If AML/ CFT regulations achieved their intended goal within the formal sector, it followed that these mysterious and entirely unregulated underground banking networks would become drug smugglers' and terrorists' financial vehicle of choice - always supposing that was not already the case. Nor did such a prospect appear to be merely hypothetical. As readers promptly began to be reminded in sensationalist articles in the press, innumerable unlicensed and unregistered store-front operators serving Muslim communities in North America and Western Europe were busy sending huge sums to all manner of exotic destinations in Asia and the Middle East through a shadowy money-transmission system known as hawala. In the paranoid atmosphere which grew up in the aftermath of 9/11, little additional imagination was required to join up the dots, and to reach the conclusion that these largely Muslim controlled hawala networks - together with a number of other similarly structured Informal Value Transmission Systems (IVTS) used by migrant communities of differing origins — were vehicles for money laundering on a global scale. IVTS networks rapidly became the prime target of renewed efforts to intercept and obstruct the activities of terrorists and drug smugglers.

FinCEN was well aware of the existence of such networks prior to the passage of the Patriot Act. Since its objective was to subject all forms of financial activity whether implemented in the formal or the informal sector - to regulatory scrutiny, the newly reinforced AML/CFT regime was also designed in such a way as to apply with equal force in both contexts. The objectives of those who designed the new regime appear to have been three-fold: first, to place ever larger obstacles in the way of money launderers seeking to process their funds, no less in the informal than the formal sector; secondly, to provide financial regulators in every country in the world with the wherewithal to place sanctions on, and ultimately to prosecute, any financial operators who had failed to conform to their model regulatory requirements; and thirdly (despite many public denials), to establish an environment in which IVTS procedures would rapidly be shorn of their remaining advantages and attractions, so much so that all the legitimate business which such systems had hitherto handled would progressively migrate into a properly regulated and auditable formal sector.

Set against that background the central objective in this paper is to explore an issue which has as yet attracted remarkably little analytical attention: the way in which IVTS networks in general — and hawala networks in particular — actually operate as transnational value transfer systems, and in doing so suggest that the secret of their financial success derives from their capacity to operate as self-regulating coalitions closely akin to those described by Greif in his well-known study of Maghribi traders. ${ }^{4}$ This in turn provides a platform from which to consider a number of further related issues, including:

- the place which IVTS/hawala networks currently occupy in the global financial order;

- the vulnerability of such networks to infiltration by criminal elements;

- the degree to which established patterns of self-regulation with such networks have kept such elements at bay;

- whether recent AML/CFT initiatives have reinforced - or merely by-passed - those self-regulatory structures;

- to review the effectiveness of the new regulatory regime from a cost/benefit perspective. 
THE INFORMAL FINANCIAL SECTOR

The most obvious way in which transactions within the informal sector differ from those executed in the formal sector is the extent to which the former are underwritten by relationships of interpersonal trust rather than by impersonal bureaucratic procedures. As a result, day-to-day financial activity produces a substantially lower volume of documentation generated within the formal sector. Even though an ever-growing proportion of financial transactions are now executed electronically, paper records have by no means been superseded. Indeed precisely because of the ephemeral character of the Ethernet, all the parties to any given transaction normally take care to store a physical record of their activities, with the result that data archives continue to follow a pattern of exponential growth. It is not hard to see why: these archives provide both internal and external auditors with an opportunity to construct a comprehensive audit trail for each and every transaction should they so wish; and that capacity provides every institution with its ultimate bastion against financial malfeasance, no less with respect to transactions with external customers than to its own internal operations. Any transaction implemented in such a way as to evade these archiving procedures - whether described as 'cash in hand', 'under the counter', 'outside the books' or 'off-balance sheet' - is an immediate source of suspicion. At their mildest errant transactions may be the outcome of efforts to evade regulatory restrictions and/or the payment of taxes; at the other end of the spectrum they point to the prospect of outright criminal malfeasance. The maintenance of comprehensive financial archives may be an expensive procedure, but given their role in ensuring the integrity of the entire financial order, investment in record-keeping is consequently regarded as a necessary cost of doing business.

\section{Migrants and remittances}

Given such expectations, the realisation that a large proportion of the world's evergrowing stock of long-distance labour migrants regularly eschew the services of the formally constituted international banking system to transmit their savings back to their kinsfolk, preferring to use informal IVTS networks instead can come as a jolt, especially since the volume of funds so transferred is anything but trivial. In the 2005 edition of 'World Economic Outlook', the IMF sets out calculations (based largely on national Balance of Payments (BoP) data) which suggest that the flow of workers' remittances to developing countries through formal channels alone currently amounts to at least $\$ 100$ bn per annum. The parallel flow of remittances through informal channels by definition eludes these published BoP statistics, which IMF staff readily admit may well significantly underestimate the true scale of transfers through formal channels; furthermore, a reasonable guesstimate of the scale of transfers through informal channels is that they amount to at least as much again, and possibly a good deal more besides. ${ }^{5}$

The reasons why migrant workers frequently prefer to use informal channels are quite straightforward. Operating out of store-front premises located conveniently close to the localities in which their customers live and work, money-transmission agents provide a service which mainline banks have found it quite impossible to match. Besides offering extremely favourable exchange rates and low commission charges, most operators guarantee cash delivery into the hands of designated recipients within the space of 48 hours, no matter how remote the destination may be. ${ }^{6}$ No wonder customers eagerly flock to their doors.

Since 9/11, however, these operations have become an endangered species. In the immediate aftermath of the attack on the 
twin towers the al-Barakaat network, one of the largest hawala networks serving emigrants from Somalia, was closed down on the grounds that its services had been utilised to finance terrorism. ${ }^{7}$ As shall be seen later, a number of hawala operators in the UK have also faced charges of moneylaundering, while in May 2005 the US Immigration and Customs and Enforcement Service proudly announced that since the Patriot Act was enacted 'a nationwide campaign against unlicensed money transmittal businesses and underground hawalas had resulted in the arrest of 140 individuals, 138 criminal indictments, and the seizure of more than $\$ 25.5$ million in illicit proceeds. 8

What is far from clear, however, is whether any of these foreclosures - almost all of which came about as a result of breaches of regulatory requirements were actually on target, at least with respect to the formal objectives of the Patriot Act. No one would contest that there is an urgent need to curb the activities of international terrorists and drug smugglers, or that coherent efforts to provide this multibillion dollar sector of the global foreign exchange market with an appropriate regulatory framework is now a priority. When politically driven demands for instant 'results' dominate the agenda, however, the temptation to cut corners can become overpowering. If these two quite separate objectives are comprehensively inter-woven as this author would suggest has occurred in the aftermath of the events of $9 / 11$ the consequences can be disastrous. First, the pursuit of regulatory breaches can become a surrogate for catching terrorists or drug smugglers red-handed. .' Secondly, and yet more seriously still, while the prospect of successfully prosecuting surrogates is undoubtedly increased if regulatory regimes are constructed with little or no awareness of just how the financial systems they are designed to oversee actually oper- ate, institution of legal proceedings based on such surrogate offences makes it next to impossible to determine whether the defendant was actively engaged in criminal malfeasance, or whether his preferred methods of business practices were based on principles with which the regulators were unfamiliar. This precipitates yet more counterproductive consequences. Once the stable door rather than the occupant of the stall behind it becomes the target, all traces of the fleeing horse - let alone of its provenance - will normally have been obliterated long before prosecutions reach court. As shall be seen, triumphs so achieved are frequently nugatory.

\section{Just what were the regulators seeking to regulate?}

Prior to the passage of the Patriot Act, the only extended empirical study of the actual operation of IVTS networks was carried out by Nikos Passas on behalf of the Dutch Ministry of Justice. ${ }^{10}$ But despite having been briefed to explore the extent to which IVTS networks were being used as vehicles for money laundering, Passas's conclusions were strikingly cautious:

'The material reviewed for this study suggests that IVTS do not represent a money laundering or crime threat in ways different from conventional banking or other legitimate institutions. While criminal entrepreneurs do make use of IVTS, it appears that the amounts involved represent a rather small part of the dirty money in circulation. The growth of IVTS for hard core criminal purposes is limited by the wide availability of numerous other alternatives ... This does not mean that sophisticated criminals cannot adopt IVTS methods to transfers funds among legitimate or shell companies around the world. However, the traditional IVTS seem to be used primarily by ethnic groups either for perfectly legitimate 
purposes or for the commission of relatively minor offences, such as evasion of taxes and currency controls... . There is little evidence that the most sophisticated and organized criminals make use of IVTS.' [italics added $]^{11}$

Nevertheless in the aftermath of $9 / 11$ remarkably little attention was paid to arguments of this kind. Even when Passas reached the conclusion that there was no evidence that such networks were either more open to, or more frequently used as, a vehicle for criminal activity than more conventionally organised financial institutions, while there was plentiful data indicating that they had entirely legitimate foundations as a cheap and effective vehicle for the transfer of migrant remittances, the tide was already flowing in the opposite direction. As Passas himself noted, erroneous statements about IVTS were being uncritically reproduced in government reports, academic publications, and even UN documents, so much so that a great deal of what passed for knowledge in this sphere was best regarded as little more than the outcome of the creation of 'facts by repetition'. Little did he know how right he was. Despite the publication of a number of reports following aspects of his ground-breaking study, ${ }^{12}$ empirically grounded information on the day-to-day operation of IVTS networks remain extremely sparse. Meanwhile efforts to comply with the requirements of AML/CFT have turned the manufacture of 'facts by repetition' into what can only be described as a global industry. ${ }^{13}$

\section{THE HISTORICAL ROOTS OF CONTEMPORARY HAWALAIIVTS NETWORKS}

In the light of glaring post 9/11 headlines suggesting that IVTS networks threatened the very foundations of the established socio-political order, it is worth remember- ing that the dramatic increases in the scale of value transfers through such networks during the closing decades of the twentieth century can be traced to much more mundane sources. As a result of rapid economic growth in Euro-America - as well as in the oil-rich areas around the Gulf, and more recently still around the East Asian sector of the Pacific Rim - ever-greater levels of affluence have led local residents to retreat en masse from unattractive jobs at the menial end of the labour market. As a result an ever-growing number of migrant workers - most of whom originate from relatively poverty stricken rural areas elsewhere in Asia, North Africa and Latin America - have made their way north and west to fill the gaps in local labour markets. Now tens of millions strong, migrants of non-European origin now make up a significant component of the urban labour force in most parts of the developed world. Like their counterparts of European origin who settled in the New World a century ago, ${ }^{14}$ most remain in as close, if not closer, touch with their family and kinsfolk back home, to whom they remit a significant proportion of their wages. Given that most are employed as unskilled labourers, their earnings are relatively meagre, especially in the early years of settlement. Hence they are rarely in a position to send more than a few hundred dollars a month back home to support their families. But while the size of each such remittance is relatively small, the number of remitters is large: hence the huge scale of the global transfer market noted earlier. Nevertheless organising the reliable delivery of these remittances to often obscure destinations is an extremely logistical task.

Relatively few migrants' families have easy access to the formal banking system, especially if they live in rural areas. Moreover as migrants soon discovered, sending small sums through formally constituted 
banks, as well as specialist services such as Western Union, does not come cheap: for small sums, commissions are never less than 10 per cent, and often considerably more; exchange range spreads are normally substantial; transmission speeds can frequently be excruciatingly slow, especially if the transaction is passed through the cumbersome bureaucratic procedures so often still maintained by state-owned banks in the developing world; and even if funds can be transferred to an accessible location, the social status of the recipient is often so low that the funds themselves can be difficult to extract. It was in these circumstances that informal transfer mechanisms came into their own. Organised by members of the migrants' own communities, and untrammelled by the expense and necessary delays precipitated by formal bureaucratic procedures, hawaladars contrived to arrange the swift, reliable and low-cost delivery of remittances directly into the hands of recipients, no matter how remote their place of residence. Scoring hugely in terms of speed, reliability, cost and convenience, informal systems enjoyed a position of very substantial advantage over the competitors in the formal sector. ${ }^{15}$ No wonder they became migrants' transfer vehicle of choice.

None of these networks sprang into existence out of the blue: each was grounded in a specific group of migrants' ancestral values and traditions, and in modes of exchange and value transfer which usually had lengthy historical roots. In the case of hawala, these lay in the commercial banking operations devised by merchants engaged in long-distance trade in and around the Indian Ocean region in the precolonial period. These networks are extremely ancient. Archaeological excavations have uncovered quays and harbours supporting trade between the Indus delta and Mesopotamia as long ago as 2000 BCE. By Roman times the deep-sea route between the Red Sea and Southern India - a voyage which took advantage of the annual shift in the prevailing winds associated with the monsoons - was in regular use. ${ }^{16}$ When Roman dominance in the Mediterranean region was replaced by that of the Arabs, the scale of trade in and around the Indian Ocean expanded enormously. So, too, did the presence of Islam throughout the region, since the majority of those involved in long-distance trade were - or became - Muslims. It was precisely such traders who initially established local Islamic bridgeheads in India, along the coast of East Africa, in Malaysia and Indonesia, as well as in numerous Chinese ports; since hawala (understood as 'the transfer of debt ${ }^{17}$ ) was by then the usual means whereby Muslim merchants operating out of the Red Sea financed long-distance trade, they took the system with them as their networks spread out across the Indian Ocean. ${ }^{18}$

Given the ever-growing scale and complexity of long-distance traders' activities, one of their most pressing financial needs was some means of facilitating value-transfers between the various ports and markets in which they did business. In their absence traders would be faced with the expensive - and dangerous - burden of transporting large sums of bullion over long distances. Hence hawala initially emerged as a secure and effective means whereby long-distance traders could finance their activities. The growth and development of contemporary hawala networks is best understood in the context of an appreciation of how these ancient systems operated.

\section{The role of hundi in hawala transactions}

Hawala networks initially emerged in a context which was very different from that with which we are familiar today. Communications were dramatically slower, external enforcement mechanisms were 
largely absent, and principals - especially those engaged in organising long-distance value-transmission - rarely had an opportunity to meet one another face to face: indeed they might well never do so at all. It is also worth identifying the specific character of the transactions for which they were responsible. Although hawala (whether in its ancient or its contemporary modern format) is regularly described as a 'banking' system, hawaladars were (and are) in no sense money-lenders or deposit-takers. No interest was charged on debts or expected on deposits: while the principle of interest was well known, money-lenders formed another speciality altogether. ${ }^{19}$ With this in mind hawaladars (ie those who facilitate hawala exchanges) can best be identified as specialist value transmission agents utilising a network of reciprocities with partners like themselves to facilitate value transfer on their clients' behalf as between spatially separated financial arenas. ${ }^{20}$

From this perspective hawala can also be regarded as a specific instance of a more general class of Informal Value Transfer operations, in which the notion of a 'transfer of debt' (the original Arabic root meaning of the term hawala) provides a means of financing long-distance trade in a manner congruent with the prescriptions of classical Islamic law. Within that context the key financial instrument by means of which hawaladars serviced their customers' needs was the hundi: effectively a bill of exchange. ${ }^{21}$ Using instruments of this kind, a trader could deposit his working capital with a hawaladar operating out of his home base, in exchange for a hundi which was negotiable either in whole or in part from the issuing hawaladar's corresponding partners in a range of distant markets; and once his business was done in any given market he could translate his profits into a similar instrument issued by a local hawaladar, ready for use either in the next trading centre to which he moved, or simply to be encashed as profit once he finally returned to his home base.

Hawaladars who issued such hundis appear to have used all the well-established procedures of commercial banking. In major Indian Ocean ports such as Hormuz, Surat or Malacca where long-distance trade was extensive, each hawaladar might well find himself issuing and encashing dozens of hundis every day: and so long as each operator could engineer his business in such a way that daily inflows and outflows of specie were broadly equivalent, a relatively small commission on each transaction could be the basis of a very profitable business. Of course some of the hundis issued in this way might well be used to facilitate deals between traders operating in the immediate vicinity of the port, and would therefore return straight to the issuer for encashment. By far the largest and most significant transactions underwritten by hawaladars, however, were those contracted by long-distance traders arriving from, or setting off to, markets located many hundreds of miles away. Hence hawaladars engaged in the issue of hundis were anything but stand-alone operators: each formed a node in a network of corresponding partners based in major trading centres spread across a large geographical region, within which all were prepared to honour each others' financial instruments. In the vocabulary of contemporary computing such networks can usefully be described as secure distributed systems, and in that of games theory as coalitions.

From the customer's perspective, a hundi is best understood as a straightforward promissory note which is encashable on presentation to any one of the system's many spatially scattered front offices: in practice, a well-known hawaladar, or failing that his agent, sitting right there in the middle of the marketplace. In back-office terms, however, the execution of each such hundi added yet further to a pre-existing standing 
relationship of debt (or credit) as between himself and whoever issued the instrument in the first place. In the absence of any external means of enforcing any aspect of these transactions, trust was a necessary prerequisite for the reliable operation of the whole system. Not only did each customer need to be confident that his hundi would promptly be honoured by any of the issuer's partners to whom he presented it, but each distant encasher needed to have an equal degree of confidence that any disbursement made would be settled in due course. This was crucial: in the absence of a robust and effective means of guaranteeing settlement, the whole system would rapidly have collapsed.

\section{Hawala as a vehicle for settlement}

How, then, was this avoided? Within such a multi-nodal value transmission network, each participating hawaladar stood in a constantly shifting position of debit or credit with respect to those operating at each of the other nodes of the network. Moreover, during seasons when the winds were adverse and trade was poor, internodal debts could grow extremely large. In these circumstances the central challenge was to establish a reliable means of securing and settling such debts, even though the only means of communication was via the uncertain progress of camel caravans and sailing ships. The construction of networks of absolute mutual trust was the obvious answer: once such a network was in place every hawaladar could be confident of ultimate settlement no matter how great the cumulative debt he temporarily found himself carrying. That said, the scale and complexity of the Indian Ocean's trading systems, together with the extent to which these formed a single financial universe, rendered the prospect of arranging such debt-settlements without undue delay a good deal brighter than one might suppose. If exchanges along any given trade route were broadly in balance, it followed that in the short to medium term debts running in opposite directions could routinely be struck off against each other - so much so that the net transfer required to settle the imbalance between any two nodes would invariably be very much smaller than the gross value of the transfers between them. Multi-nodal settlements were inevitably more complex, but the same principles still applied.

Just as with any clearing bank, the process of issuing and honouring hundis on behalf of retail customers was a relatively trivial task as compared with the implementation of a system of settlement through which a complex web of debts could be settled on a reliable basis. Moreover, in this case settlements had to be achieved in a context where communications travelled at the speed of the fastest ship or camel, and in the absence of any coordinating headquarters - let alone an external agency - through which to resolve disputes or enforce agreements.

\section{Strategies for underwriting the security of settlement}

Regardless of whether the context in question is modern or premodern, two key conditions must hold if such commercial settlements are to be reliably completed. First, every participant must be confident that all potential business partners will routinely fulfil all bargains, and secondly they must also have access to effective sanctions should anyone fail to do so. It is precisely in order to fulfil these conditions that contemporary banking systems operate within the context of a complex mesh of nationally and internationally enforced legal and regulatory frameworks, and subject their operations to regular audits, both internal and external. The object of doing so is two-fold. First to underpin the stability and security of the financial system as a whole, and secondly to assure their custo- 
mers that their assets have not been and will not be mislaid. Contemporary IVTS networks arouse suspicion because they appear to have no way of fulfilling these conditions, and consequently to be wide open to malfeasance.

How far are these conclusions justified? In addressing that question it is worth remembering — as has just been seen that bankers, traders and value transmission agents in the premodern period faced just the same challenges as their contemporary counterparts, but nevertheless managed to construct a tolerably secure - but largely non-bureaucratic — financial order within which to conduct their business. How, then, did they achieve this outcome, given that even the most fervently committed Muslims readily acknowledged that it was hopelessly idealistic to assume that fear of divine punishment would be a sufficient bastion against cheating? Ethnographic observation of practices in the present and the recent past all point in the same direction. Eschewing the contemporary EuroAmerican assumption that all transactors are best advised to treat each other as if they were unreliable and hence potentially malfeasant 'strangers', the premodern tendency was to assume that all such transactions should have a social as well as a financial dimension, and hence that they would normally be conducted within the context of a set of long-term reciprocal understandings between those involved.

In these circumstances long-distance traders, and above all those who provided the financial infrastructures which grew up to support their activities, ordered their business on the very inverse of the assumption that they and their customers were a bunch of mutually distrustful strangers. Instead, they formed a series of tightly knit networks, within each of which all participants stood in a position of absolute trust with respect to one another. The resulting relationships of reciprocity were by no means confined to the sphere of business activity: rather they extended into - and indeed were underpinned by - a multidimensional web of interpersonal reciprocities, such that all those involved in the network were bound together into a selfsustaining and self-ordering community. This also gave rise to a highly effective sanction for malfeasance: excommunication of the offender and all his kinsfolk. In a world of tight-knit communities, excommunication was synonymous with social death.

Communities constructed on this basis lend themselves to trans-local extension, since both the patterns of reciprocity which underpin them and the sanctions which guaranteed them, can readily be sustained even in the absence of daily face-to-face contact between participants. Hence premodern trading networks were for the most part composed of people with distinctive linguistic and religious commitments whose pursuit of trade had led them to form wide-ranging diasporas, whose internal coherence was continuously reinforced by trans-local ties of kinship and marriage, and very often by sectarian religious commitments as well. ${ }^{22}$

\section{The dialectics of trust in trans-local commercial networks}

In seeking to comprehend the effectiveness of network-grounded reciprocity as a means of sustaining system security, observations of contemporary practice can usefully be set alongside the findings of economic historians. The concerns of the latter were precisely the same as those which confront us here: how were disputes settled, and malfeasance curbed prior to the emergence of state-enforced regulatory and/or legal structures? In this respect Greif's well-known study of the activities of 11th-century Arab/Jewish traders in the Maghrib is of particular interest, not least because he analyses practices in the same 
geographical and cultural milieu as that from which hawala emerged. His conclusions are worth quoting at length:

'The Maghribi traders overcame the contractual problems associated with agency relationships ... through a nonanonymous organizational framework, the coalition. Within the coalition an internal information-transmission system served to balance asymmetric information and a reputation mechanism was used to ensure proper conduct. This reputation mechanism explains the observed "trust" relations among the traders. The "trust" did not reflect a social control system or the internalization of norms of behaviour (although these factors play a role in any economic system). Rather, the Maghribi traders established a relationship between past conduct and future economic reward. As a result, agents resisted the short-term gains attainable through deception, since the reduction in future utility resulting from dishonest behaviour outweighed the associated increase in present utility. Since this fact was known beforehand to all traders, agents could acquire a reputation as honest agents ...

The common religious-ethnic origin of the traders provided the natural boundaries for the coalition and served as a signal where information regarding past conduct could be obtained, while the commercial and social ties within the coalition served as a network for the transmission of information. The information-transmission mechanism generated by the social structure - the Maghribi traders group - supported the operation of an economic institution the coalition. On the other hand, this economic institution, which promoted organizing agency relations only among members of this social structure, motivated the Maghribi traders to interact and thus to preserve their social structure, their distinct identity within the Jewish world. ${ }^{23}$

As Greif has gone on to argue, his analysis is also capable of generalisation to all manner of other trust-based commercial coalitions, ${ }^{24}$ including Indian Ocean hawala networks in both their ancient or modern formats, and in principle most other contemporary IVTS initiatives as well. But if this is indeed the case, are such coalitions merely a discrepant mediaeval hangover whose contemporary vitality existence is primarily dependent on their capacity to support criminal malfeasance? Or are they, on the contrary, a rational and creative response to some specific commercial challenges, and their trust-based modus operandi is precisely the reason why they frequently enjoy a position of competitive advantage over more bureaucratically constituted operations?

\section{THE ECLIPSE AND REVIVAL OF HAWALA NETWORKS}

When European adventurers initially broke into Indian Ocean trading systems in the 16th century, they had little alternative but to make extensive use of locally constituted financial services, if only because extant commercial networks in the region were a great deal more sophisticated than their own; ${ }^{25}$ and for straightforward commercial reasons, European merchants and administrators operating in more peripheral areas continued to make use of such local value transmission systems until well into the 19th century. ${ }^{26}$ By then, however, European domination had become a great deal more extensive, such that European-style financial institutions occupied the commanding heights in all the Indian Ocean's major trading centres. In consequence, indigenously ordered financial services found themselves pressed outwards towards the geographical and economic periphery 
of the imperial economy, where the pickings were too slight to be of much interest to European-owned banks and trading houses.

While virtually all newly independent postcolonial states inherited a plural financial system, in the sense that Western-style financial systems stood at the core while more traditional structures still flourished at the periphery, ${ }^{27}$ most promptly took active steps to yet further extend the reach of the formal sector, often in a nationalised format, at the expense of more informal practices: influential theories of progress and modernisation held that they could do no less. Yet despite consistent efforts to eliminate the informal sector throughout the developing world, it has continued to thrive - and nowhere more spectacularly so than in transnational contexts. Four key developments have facilitated this process of resurgence. They include:

- the imposition of over-tight exchange controls by many newly independent postcolonial states, with the consequent emergence of 'black' markets in foreign exchange;

- the huge outflow of labour-migrants to the Gulf and Euro-America, and a consequent massive return flow of migrant remittances;

- the rapid growth of manufacturing activity in East and South East Asia leading to an upsurge in intra-regional trade in manufactured goods;

- radical improvements in communications technology, including fax, internet, cell- and satellite phones.

Taken together, these developments gave rise to an arena within which hawala networks rapidly gained a new lease of life: not only did migrant remittances provide an ever-expanding source of hard-currency liquidity, but the institutionally blocked demand for foreign exchange among com- mercial enterprises in labour-exporting countries provided a ready counter-flow of value against which to broker settlements. Moreover, as far as migrants from postcolonial states were concerned, the attractiveness of the informal sector was further reinforced by the sclerotic character of the banking sector in their countries of origin, such that the provision of financial services in rural areas was invariably extremely poor. Meanwhile the hawaladars' rapid utilisation of improvements in communications technology enabled them to run their 'informal' systems in an ever more sophisticated way, so much so that they have been able to gain a position of substantial competitive advantage over institutions operating within the formal sector.

\section{How do contemporary hawala/IVTS systems actually work?}

Contemporary hawala networks, like other similarly structured IVTS operations, derive a large part of their success from their exploitation of a specific niche in the forex market: the transfer of value between different currency regimes on behalf of small-scale customers. The key to their success in this sphere has been two-fold. First, the construction of highly efficient structures through which to collect, consolidate, transfer, deconsolidate and finally to distribute large numbers of relatively small packets of value - enabling them to deal very effectively with first mile/last mile problems. Secondly, by redoubling the commercial efficiency of the whole operation by brokering parallel transfers in the reverse direction, enabling settlement to be implemented on an in-house - or to be more precise on a within-the-network basis.

Contemporary counter-transfers are very different in character from the multiplicity of penny-packets characteristically dispatched by migrant workers. Besides being made up of very much larger tranches of 
value, such transfers also take place for quite different purposes. At present most appear to be derived from three key sources. First, from commercial enterprises settling invoices for goods imported from overseas suppliers; secondly, from members of affluent local elites financing the purchase of health care, educational services and so forth overseas; and thirdly, from such institutions and persons taking the opportunity to tuck away financial assets in safe havens overseas.

Implementing the transfer and delivery of these differently structured streams of value - let alone completing the necessary processes of settlement - is a daunting logistical challenge. ${ }^{28}$ The way in which this is achieved is most illuminating. Contemporary remittance-driven hawala operations appear to have three core elements, all of which are closely inter-connected. They include:

\section{Information processing}

- provision of current exchange rates to prospective senders;

- collection of data from senders about how much is to be delivered in what currency, where and to whom;

- transmission of delivery data to the remote destination.

2. Value transmission and settlement

- provision of credit at the point of delivery, since delivery invariably precedes settlement;

- identification of soft-currency funds with which to make that settlement;

- brokering the necessary transnational and cross-currency settlements.

3. Collection and delivery of currency notes

- collection and consolidation of senders' deposits, and the onward transmission of these funds to settlement partners;

- deconsolidation of credits received from settlement partners, and their distribution to assigned recipients at a variety of overseas destinations.

In this schema hundis have largely disappeared from the picture: improvements in communications technology have rendered them largely redundant as vehicles for the implementation of this form of value transmission. Other aspects of the hawala system, however, remain as important as ever, as a concrete example of contemporary practice will serve to demonstrate.

\section{A concrete example: The transfer of remittances from the UK to Pakistan's Mirpur District}

Rather more than a third of a million people whose ancestral origins lie in the Mirpur District are resident in the UK, most of whom keep in close touch with their kinsfolk back home. ${ }^{29}$ Not only are visits back and forth extremely frequent (PIA operates no less than ten flights into Manchester every week), but many of the pioneer settlers who arrived in the UK 40 years ago have now retired, and are now taking the opportunity to use their accumulated savings to build splendid new houses for themselves back in Mirpur. As a result remittances from the UK to Mirpur are currently running at somewhere in the region of $£ 250 \mathrm{~m}$ per annum, the greater part of which passes through hawala networks. In doing so delivery is routinely achieved within 48 hours, with no significant organisational fuss and 100 per cent reliability. From the customer's perspective, sending money back to Mirpur could hardly be more straightforward. All they have to do is approach their local Pakistani travel agent (the vast majority of whom offer such services, either in their own right, or as the agent of a larger hawala operator based in a city with a large local Pakistani population), enquire about and agree upon a rate of exchange, make the agreed payment, and provide the hawaladar with the 
recipient's name and address in Mirpur: within 48 hours the sum agreed upon will be ready for collection in Mirpur. ${ }^{30}$

So how is it all achieved? As ever the back-office mechanisms which support these apparently straightforward frontoffice results are extremely complex. As a result they are best considered in a series of stages, all of which have to fit smoothly together to produce the desired result.

\section{Step 1: The collection of sterling in the UK and the delivery of rupees in Mirpur} In front-office terms, hawaladars engaged in collecting and dispatching remittance transfers work in close collaboration with corresponding partners operating at the destination(s) to which those remittances are dispatched. Leaving the issue of settlement to one side for the moment, implementing that component of the deal which matters to the customer - the delivery of rupees to the recipient — is primarily dependent on the swift and accurate transmission of the appropriate delivery instructions. But to send a separate message for each and every transaction would be highly inefficient: hence consolidation is the order of the day. Each consolidating hawaladar (and for clarity's sake let us identify him as $\mathrm{H}^{\mathrm{a}}$ operating in Birmingham) consequently makes up a list — as like as not compiled on an Excel spreadsheet — setting out all the transactions brought to him by over-the counter customers during the course of the day, together with those passed on to him by a network of agents and sub-agents operating in smaller Pakistani communities elsewhere in the UK, which is then faxed to his corresponding partner $\mathrm{H}^{\mathrm{b}}$ in Mirpur. ${ }^{31}$ Having received the fax, $\mathrm{H}^{\mathrm{b}}$ can promptly set about organising the local delivery of rupees to recipients as instructed - and, where necessary, using his own network of agents and sub-agents to make deliveries to recipients resident in villages in the more remote parts of the district.
To sum up what has been achieved so far:

- Community networks have been used to facilitate consolidation and de-consolidation at each end of the transmission chain, incurring minimal administrative costs.

- Deliveries have been organised in response to faxed instructions which provide details of each sender, each recipient, and the amount due; detailed records are necessary prerequisite to accurate delivery.

- $\mathrm{H}^{\mathrm{a}}$ has acquired a debt/liability to $\mathrm{H}^{\mathrm{b}}$, but as yet there has been no transfer of value from $\mathrm{H}^{\mathrm{a}}$ to $\mathrm{H}^{\mathrm{b}}$. At some stage this debt must of necessity be discharged.

\section{Step 2: The organisation and implementation of settlement}

Given that the majority of migrant workers are drawn from remote rural areas, it follows that distributing hawaladars relatively rarely operate in regions where there is no significant local demand for foreign exchange. That is certainly the case in Mirpur. Hence $\mathrm{H}^{\mathrm{b}}$ rarely if ever has local customers interested in exchanging rupees for the sterling credits which he is constantly accumulating with $\mathrm{H}^{\mathrm{a}}$ in Birmingham. But in Karachi, Pakistan's commercial capital nearly a thousand miles away to the south, there is an almost insatiable demand for hard currency, for which buyers are usually prepared to pay premium rate. ${ }^{32}$ Hence, the informal moneymarkets in Mirpur and Karachi are effectively mirror-images of one another. In a pattern which is replicated in many other countries in the developing world, remittances have generated a huge demand for local currency in the areas from which the majority of migrants are drawn, matched by an equally acute demand for hard currency among the more affluent sections of 
the population, most of whom reside in a few major cities. This state of affairs provides obvious opportunities to organise and implement complementary back-to-back settlements.

\section{Karachi's hawala market}

As compared with hawaladars serving the needs of migrant workers, their counterparts in Karachi operate in a very different kind of financial context. Since the majority of their customers are drawn from the city's business and professional elite, their orders for US dollars are invariably on a substantial scale, so much so that a single order might well generate a sufficient quantum of rupees to meet a week's worth of $\mathrm{H}^{\mathrm{b}}$ 's daily penny package out-payments in Mirpur. But while organising the bulk transfer of the requisite volume of rupee currency notes from Karachi to Mirpur requires no more than the hiring of armed guards to look after the shipment, a further swap must also be implemented before the remainder of the circle is closed. Final settlement can only be achieved when the hard-currency credits held by $\mathrm{H}^{\mathrm{a}}$ in Birmingham have been transferred to the destinations specified by the customers of $\mathrm{H}^{\mathrm{c}}$ in Karachi.

\section{The role of Dubai as a settlement hub}

Most such Karachi-based deals are currently brokered in Dubai. Why Dubai? Thanks to the boom in the price of oil Dubai not only managed to establish itself as the Gulf's most important commercial entrepôt, but as a result of its proximity to Bombay and Karachi, the dirham's fixed link to the dollar, and its consequent condition of unrestricted access to the global financial system, Dubai has become South Asia's premier offshore banking centre. As a result the Exchange Houses of Dubai, virtually all of which are run by migrants of South Asian origin, have come to play a key role as facilitators of remittance and commercially driven hawala settlements on a global scale. Hence from a newly established hub in Dubai, hawala networks which have their roots in mediaeval practices are again playing a very active role in oiling the wheels of trade in the entire Indian Ocean region.

\section{A worked example}

With all this in mind, a worked example - albeit much simplified - may provide a clearer and more concrete indication of just how the whole settlement process operates. Let us suppose that $\mathrm{H}^{\mathrm{a}}$ in Birmingham has taken orders for the delivery of Rs10m in Mirpur, for which he has received $£ 75,000$ from his UK-based customers. Meanwhile $\mathrm{H}^{\mathrm{c}}$ in Karachi has a customer who wished to purchase $\$ 100,000$ in order to settle the invoice for a consignment of televisions which he has imported from China, whose manufacturer is expecting payment to be made into his US dollar account in Hong Kong. $\mathrm{H}^{\mathrm{a}}$ and $\mathrm{H}^{\mathrm{c}}$ separately approach a specialist settlement broker in Dubai, $\mathrm{H}^{\mathrm{d}}$, who calculates (for the sake of argument) that Rs10m = US\$100,000 = £75,000, so generating an ideal opportunity to arrange a back-toback swap. Hence $\mathrm{H}^{\mathrm{d}}$ sets up a hawala settlement in which $\mathrm{H}^{\mathrm{a}}$ buys $\$ 100,000$ on the London money market through his bank which he promptly sends by TT to $\mathrm{H}^{\mathrm{d}}$, s account with the Bank of America in New York; meanwhile $\mathrm{H}^{\mathrm{c}}$ takes delivery of Rs10m in cash from his televisionimporting customer, which he promptly despatches by road to $\mathrm{H}^{\mathrm{b}}$ in Mirpur, thereby recompensing $\mathrm{H}^{\mathrm{b}}$ for the disbursements made in response to $\mathrm{H}^{\mathrm{a}}$ s previously faxed instructions; and to close the whole deal, $\mathrm{H}^{\mathrm{d}}$ transfers $\$ 100,000$ by Swift or TT from his account in New York to the television manufacturer's account in Hong Kong.

It goes without saying that the example cited is hugely simplified, and that in prac- 
tice most settlements are a great deal more complex. Indeed if matters were so straightforward, there is every prospect that $\mathrm{H}^{\mathrm{c}}$ in Karachi might approach $\mathrm{H}^{\mathrm{a}}$ in Birmingham directly, and having found a neat match between their immediate financial requirements the two would do a simple swap between themselves, thereby cutting $\mathrm{H}^{\mathrm{d}}$ (and his small percentage cut) out of the deal. Indeed precisely because everyone in the system is constantly seeking to construct such cut-out deals, brokers in Dubai - whose principal asset is a global network of trading contacts invariably play their cards extremely close to their chest. Hence they rarely, if ever, provide an indication of the other clients on whose behalf they are acting.

Such brokers are also in active competition as between themselves, and consequently constantly seeking to outwit their rivals. Hence, for example, Dubai-based brokers regularly trawl for clients in the UK. Besides tempting local hawaladars to pass business their way by offering a marginally more attractive $\$ / \mathrm{Rs}$ conversion rate, they also seek to cultivate more substantial business clients, such as Asian cashand-carry clothing wholesalers whose suppliers in South Asia and the Far East are by no means averse to having all or part of their invoices settled through informal channels. It follows that the settlement deals which brokers construct are often extremely complex. Opportunities to implement neatly matched inter-currency swaps such as that cited in the above example are rare: in practice the chips on the table are invariably composed of large but irregularly sized sums deriving from and going to a wide variety of destinations in a multiplicity of different currencies. Hence settlements invariably require the lubricating assistance of skilled and well-informed brokers if they are to be swiftly and smoothly implemented.

Physical cash plays little or no role at this level, since the basic unit of account in making such settlements is US\$100,000, multiples of which are put together to close a single deal. Such transactions are invariably completed by electronic transfers, most usually between accounts held by hawaladars and their clients in major international banks in New York. ${ }^{33}$ Examination of these accounts also suggests that while migrant remittances flowing from developed to less developed regions provide the greater part of the system's hardcurrency liquidity, they are by no means its only source: just as in Karachi, a significant number of UK-based commercial enterprises - most of which appear to be Asian owned - also use the system to meet the invoices of their overseas suppliers.

\section{System security and financial efficiency}

Dubai-based brokers by no means restrict themselves to providing settlement facilities for UK/Pakistan transfers: they also perform the same role for migrant workers based in most parts of Western Europe and North America, and to this author's knowledge are in a position to facilitate value deliveries to Somalia, Iraq, Iran, Afghanistan, Pakistan, Nepal, India and Central Asia - and doubtless many further destinations in East and South-East Asia as well. They also facilitate transactions for commercial enterprises on what appears to be a truly global scale. In doing so billions of dollars are processed through Dubaibased IVTS/hawala networks every year. Yet despite the absence of any kind of central registry, let alone external regulatory scrutiny, serious customer complaints are virtually unknown. How can this be? By now the basic answer should be self-evident: like the precolonial structures from which they evolved, contemporary hawala networks are best understood as distributed systems in which system security is rooted in the transnationally extended relation- 
ships of absolute trust between participating hawaladars. Given that all members of the network have a powerful interest in maintaining the integrity of the whole exercise, system security is a matter of collective concern. Hence in a manner wholly congruent with Greif's predictions, not only do contemporary hawaladars go to great lengths to maintain their reputation for honesty vis-à-vis each other, but they know that there is no escape from sanctions against malfeasance when electronic communication ensures that any doubts about a network member's reputation can be spread instantly round the globe.

Moreover with a historical perspective in mind, we should not be surprised at the vitality of such practices. Economic historians inspired by Greif's model have shown that his approach is equally applicable in a range of more recent Euro-American contexts, including the Amsterdam Bourse during the 17 th century, ${ }^{34}$ the City of London a century later, ${ }^{35}$ as well as mid19th century California. ${ }^{36}$ Given that the cultural resources for the maintenance of such coalitions are still in place in 21st-century Dubai - as well as in Hong Kong and Singapore for that matter - it is only to be expected that similar structures are still in use in such contexts, most especially since they provide such a highly effective means of guaranteeing system security while also promoting financial efficiency. As Greif puts it:

'By reducing agency costs and other transaction costs, the coalition promoted efficiency. It enabled operation through agents, even when the cost of establishing agency relations between a specific merchant and an agent in isolation was prohibitively high. In addition, the Merchants' Law economized on negotiation cost, governed the transmission of information and the provision of services, and substituted comprehensive contracts in the relations between a specific agent and merchant. ${ }^{37}$

It is with precisely such considerations in mind that the competitive advantage which 'informal' — or to be more precise, 'trust-based' — value transfer systems so often find themselves springs immediately into focus. Specialising as they do in the narrow - but still substantial — niche in the forex market, their prime source of competitive efficiency derives from their ability to discard as operationally redundant large swathes of clerical and bureaucratic activity deployed within the formal sector, replacing them wherever possible with relationships of trust. That said, IVTS networks are in no sense 'systems without records'. Quite the contrary: accurate data transmission is a key to their success. But by stripping out layers of redundant clerical activity and by making the most of ongoing developments in IT, IVTS networks have cut their information transmission costs to a fraction of those incurred by more formally constituted agencies.

\section{Information transfer in trust-based networks}

So just what information is transmitted through such networks? All this author's observations suggest this is normally limited strictly to that which is necessary to enable the recipient to carry out his instructions. Hence in the example cited earlier, $\mathrm{H}^{\mathrm{a}}$ in Birmingham would fax voluminous instructions to $\mathrm{H}^{\mathrm{b}}$ in Mirpur as to exactly how much should be delivered to a long list of recipients; likewise $\mathrm{H}^{\mathrm{a}}$ would also regularly receive instructions from $\mathrm{H}^{\mathrm{d}}$ in Dubai with whom he had previously cut a deal as to the sums to be transferred by TT in US dollars to bank accounts in New York. Moreover just as $\mathrm{H}^{\mathrm{b}}$ in Mirpur would probably not know (and would certainly not need to know) where the funds 
dispatched to him by $\mathrm{H}^{\mathrm{a}}$ had come from, $\mathrm{H}^{\mathrm{a}}$ would be even less likely to know who the ultimate recipient of the funds he had transferred in US dollars might be. Similarly, while $\mathrm{H}^{\mathrm{d}}$ would have a clear overview of both sides of his wholesale swap, he would have had no knowledge of the multiplicity of smaller deals $\mathrm{H}^{\mathrm{a}}$ and his associates had made with their many partner $\mathrm{H}^{\mathrm{b}} \mathrm{s}$.

Within this highly competitive distributed system (for hawaladars at every level are in constant competition with one another) participants have not only adopted a 'lean and mean' approach to data transmission between themselves, but have also taken immediate advantage of every new development in communications technology. International subscriber dialling and mobile phones were a substantial advance over telegrams, and from there hawaladars have moved rapidly onwards to use fax, e-mail, network portals and Virtual Private Networks as vehicles for information transmission, while all the larger operators - and an ever-increasing number of smaller ones - now plug directly into inter-bank electronic systems such as TT, BACS and Swift as a means of value transfer.

Given these developments, care must be taken in assessing the significance of the term 'informal' when used as a descriptor of IVTS networks. Informality in this context has nothing whatsoever to do with casual 'back of an envelope' methods of record keeping. Instead 'informality' is better understood as an artefact of participants' success in building binding networks of inter-personal reciprocity on a transnational basis, which in turn provide a means of implementing a highly specific form of financial activity: the exchange and transmission of value on a global scale. By confining themselves to this specific niche, and by generating a secure but distributed system to implement what at first sight appears to be an impossibly challenging logistical task, hawaladars and other IVTS operators have been able both to lower administrative costs and to implement 'just in time' methods of value delivery. It is on precisely this basis that they owe their current position of competitive advantage vis-à-vis their more formally constituted rivals.

\section{EXTERNAL INTERVENTION}

In the UK as elsewhere, there was a substantial delay between the initial emergence of these logistical networks from within local South Asian ethnic colonies and the point at which regulatory authorities began to take serious cognisance of these developments. At one level the reasons for delay were quite straightforward: at the outset the value transfers were so small, and the networks were ordered in such a casual way that no one outside the colonies themselves had much prospect of detecting their existence. However subterranean the initial hatching of these initiatives may have been, it did not take long before they surfaced into public view - most usually through a store-front presence, frequently in combination with a travel agency providing migrant workers with cheap tickets for visits back home.

As soon as the through-put of cash in any given outlet became substantial - as was immediately the case when consolidating hawaladars began to process the cash takings on behalf of ever-widening networks of agents and sub-agents - their role as money-transmitters became much more self-evident to outsiders. By the close of the millennium the most successful operators had opened US dollar accounts with their local banks, arranged for a live feed of exchange rates to be piped directly to their offices, and had made arrangements with Securicor or Brinks to collect trunks of ready-counted cash for delivery to their bank on a daily basis. Nor was there any 
secret about the business which they were conducting. As their bankers were well aware, they were in the business of money transmission. Hence their minimum requirement was for a US dollar account to run alongside their sterling account, together with direct access to the bank's dealing room, so enabling the purchase of US dollars on the spot market. From the mid-1960s, when hawala networks first began to emerge into daylight, right up until 2000, the UK authorities made few efforts either to explore the details of these operations, or to subject them to formal regulation. Since then there has been a radical change of approach.

\section{Criminal prosecution}

In the closing years of the 1990s one of the most important strategies on which Customs and Excise had come to rely in their efforts to curb the import of heroin into the UK ran into severe difficulties: the courts began to take the view that their well-established participating informant-led programme of identifying and prosecuting UK-based drug smugglers was flawed, so much so that it had to be abandoned. ${ }^{38}$ In the face of this setback Customs and Excise decided that they had little alternative but to change course. They let it be known that rather than trying to catch drug smugglers red-handed, they would aim instead to disrupt their financial supply chains. Their new approach was highlighted in an article in the Observer, in which David Rose reported that:

'At present, about a quarter of the 1,200 UK Customs investigators devoted to fighting the drugs trade work mainly in following the huge amounts of money involved, a proportion which is set to triple over the next two years. Again, there have been significant recent successes. In one pending prosecution, it is alleged that a network of bogus travel agencies laundered more than $f_{1} 1$ bn over three years on behalf of Turkish and Pakistani traffickers, channelling funds from Britain via Dubai to Pakistan. ${ }^{39}$

By the time Rose's clearly officiallyinspired article appeared, the present author was already aware of the change in Customs' strategic priorities, since the author had been instructed to act as an expert witness by the defence in three linked prosecutions of consolidating hawaladars based in Bradford and Halifax, the first major court cases to which Customs' new initiative had given rise. ${ }^{40}$ Since then the author has been instructed to fulfil the same role in half a dozen more such cases. While the details varied considerably from case to case, the author found the three cases - all of which involved Pakistani hawaladars conducting wholesale foreignexchange business in the manner just described - to be particularly illuminating. Their records were particularly detailed, the volume of funds which they had handled was substantial - a total of more than $6600 \mathrm{~m}$ during the 18 -month period with which the prosecution was concerned - and the whole operation was set in social, cultural and territorial contexts with which the author was already thoroughly familiar.

When these cases finally came to trial one of the central issues on which the proceedings turned was the precise provenance, as well as the ultimate destination, of the funds which the hawaladars processed. Although Customs accepted that at least some of these transfers could be assumed to be genuine migrant remittances, they insisted that this was only so when it could be shown that clients had arrived in person to hand cash directly over the counter, and had given directions for the delivery of cash to a named person at a destination in Pakistan. Having set up this paradigm of a 'genuine' transfer, the prosecution noted that 
only a relatively small proportion of the funds handled by consolidating hawaladars were of this kind. Far from receiving the bulk of their business from over-the-counter customers, Customs produced surveillance evidence which revealed that the defendants had received large bulk deliveries of cash from elsewhere in the UK on an almost daily basis. While the defendants did not deny that they had received these deliveries, the prosecution insisted that unless they were able to provide an explanation of the precise provenance of these deliveries, the only sensible conclusion that the jury could reach was that these transfers must be the outcome of some form of criminal malfeasance. To reinforce this hypothesis the prosecution also noted that although the hawaladars said they were facilitating the transfer of remittances to Pakistan, their US dollar denominated bank accounts revealed that the bulk of these funds were not sent to Pakistan, but rather to New York. On this basis the prosecution argued that in the absence of any further explanation, there was only one reason why the hawaladars should have been involved in processing vast amounts of cash in this way: as part of a criminal conspiracy to launder the profits accrued by drug smugglers. Strikingly, however, Customs was able to produce very little concrete evidence that the cash in question was indeed derived from the sale of drugs, other than laboratory evidence suggesting that the level of contamination in samples of the impounded currency notes was significantly higher than that in circulation at large. ${ }^{41}$

With the burden of proof effectively reversed, the defence found itself pressed firmly onto the back foot. Even if (and indeed precisely because) the transfers processed by the accused hawaladars were entirely in keeping with the model outlined in this paper, the defendants found themselves hard pressed to provide comprehensive answers to the questions pressed on them by the prosecution, and to do so in a manner which might make any impression on a financially unsophisticated jury. The reasons are quite straightforward.

Given the spare and carefully compartmentalised manner on the basis of which hawala swaps are constructed, it followed that while UK-based hawaladars had detailed records of the ultimate destinations of the transfers which they had made on behalf of their own over-the-counter customers, as well as of the instructions which they had received from the brokers with whom they did business in Dubai, they rarely, if ever, had detailed knowledge of the precise provenance of the consolidated tranches of cash which they had agreed to process on behalf of these brokers, ${ }^{42}$ or just who the ultimate beneficiaries of the funds in US dollars which they transferred by TT to New York would be. And while they were well aware of the identity of the other UK-based hawaladars whose funds they had processed - and indeed of the Dubai-based brokers whose instructions they had followed - their partners were most unwilling to appear in court to give evidence in the UK. One can see why: even if they were not already on the charge-sheet, ${ }^{43}$ they were likely to be asked just the same questions about their own customers, and to find themselves faced with immediate prosecution if they were unable to provide adequate answers.

Such a response could be taken, at least on the face of it, to be grounds for yet further suspicion. In the first place the hawaladars were unable to conform to the most basic requirements of AML procedures, in the sense that they were unable to identify either the precise provenance or the ultimate destination of the greater part of the funds passing through their hands. Secondly, there is no reason to doubt that informal hawala networks could in principle have been used as a convenient channel through which to launder illegitimately 
acquired funds. What the author personally found alarming in all these cases, however, is that despite the extensive surveillance operations which Customs conducted prior to the defendants' arrests, in none of the prosecutions of which he has first-hand knowledge was there any concrete evidence showing that the cash in question was actually generated as the result of the sale of illegally imported drugs: instead juries were simply invited to support the hypothesis that the hawaladars must indeed have been doing just that. In these circumstances the defendants not only found themselves being invited to prove a negative, but to do so in thoroughly adverse circumstances. Although the transactions which gave rise to these proceedings occurred well over a year beforehand, the cases all came to court in the aftermath of the events of $9 / 11$. Hence the defendants almost all of whom were Muslim - faced an even steeper uphill struggle to establish their credibility. Few succeeded. So far, virtually all those who contested such accusations were found guilty as charged.

Two of these cases, however, recently came before the Court of Appeal, which quashed the convictions of all concerned on the grounds that the appellants should not have been convicted unless the Crown had been in a position to prove that they knew - as opposed to having been in a position where they should reasonably have suspected - that the cash which the hawaladars had handled was indeed the profits of drug smuggling. ${ }^{44}$ Having so ruled, the Court also took the opportunity to raise a query about the prosecution's use of a charge of conspiracy (directed at the hawala network) in pursuing these cases, politely indicating that by adopting its chosen course the prosecution has a heavier burden to discharge than it would have in order to prove the substantive charge' (ie of profiting from the sale of drugs). In other words, the Court sug- gested that the prosecution would have been in a much stronger position if drug smugglers, rather than those alleged to be the launderers of their profits, had been the central focus of the proceedings. While the Court of Appeal directed that Customs should begin proceedings for a re-trial using a differently phrased indictment within two months if they wished to continue to pursue the matter, the consequences of this ruling will almost certainly be far reaching. Not only are most of the other hawala cases in which Customs deployed similar arguments likely to be quashed on the same grounds, but the decision may well open up a new and betterinformed debate about just how hawala networks should be regulated.

\section{Adjustments to adversity}

Nevertheless there was an interval of nearly five years between the arrest of the initial group of hawaladars and their recent successful appeal, during which both hawaladars and their customers had to cope with much more hostile attitudes from the authorities. Nevertheless the market for value transfers was in no sense diminished, not least because members of the UK's Pakistani population were as committed as ever to the maintenance of their links with their homeland. Besides making frequent visits to Pakistan, they continued to remit substantial sums to support family activities back home, and to invest in house construction. How, then, did they react?

By good fortune the author was in Pakistan in the spring of 2000 - in other words immediately before the crackdown took place - exploring precisely these issues. During the course of fieldwork he was able to establish that the vast bulk of the remittance transfers from the UK to Mirpur were by then passing through the informal sector. ${ }^{45}$ The central reason for this was not hard to identify: over and above issues of speed and convenience, the 
exchange rate offered by hawaladars was substantially higher than that offered by formally constituted banks, so much so that the flow of value through the formal sector had fallen close to zero. As news of Customs' successful prosecution of hawaladars began to circulate, however, further supplemented by lurid accounts of the allegedly criminal character of hawala which appeared in the press in the aftermath of 9/11, many remitters decided to err on the side of caution: much more extensive use began to be made of formal channels, even though the transaction costs were substantially higher.

Although hawaladars have by now regained a significant share of the transfer market, the arrests in the UK, strongly aided and abetted by the global impact of the Patriot Act, had a dramatic impact on the formally recorded inflow of remittances into Pakistan: as Figure 1 shows, the Balance of Payments figures compiled by the State Bank of Pakistan indicated that the formally recorded inflow of migrant remittances from all sources during fiscal year 2003 was no less than four times greater than it had been in 2001 .

Nevertheless it would be idle to suppose that this very substantial switch into the formal sector had brought the hawala system to its knees. While there can be no doubt that migrant remittances make an enormous contribution to Pakistan's economy - just as they do in many other labour-exporting countries — interpreting the significance of the data set out in Figure 1 is far from easy. Over and above such perennial questions as precisely how migrant remittances should be defined, and how effectively local officials succeeded in distinguishing migrant remittances from those derived from other sources, there is no reason to suppose that informal remittance transfers had dried up completely by FY 2003. Moreover, the fall in the recorded inflow in 2004 seems much more likely to indicate a resurgence of activity in the informal sector than a diminution in overseas Pakistanis' propensity to remit. In other words, while the crackdown on IVTS networks which followed in the wake of the events of $9 / 11$ was undoubtedly a setback to the hawala networks operating out of Dubai, ${ }^{46}$ the damage inflicted was far from terminal: instead operators have made concerted efforts to accommodate themselves to the new

Figure 1 Annual formally recorded inflow of migrant remittances to Pakistan

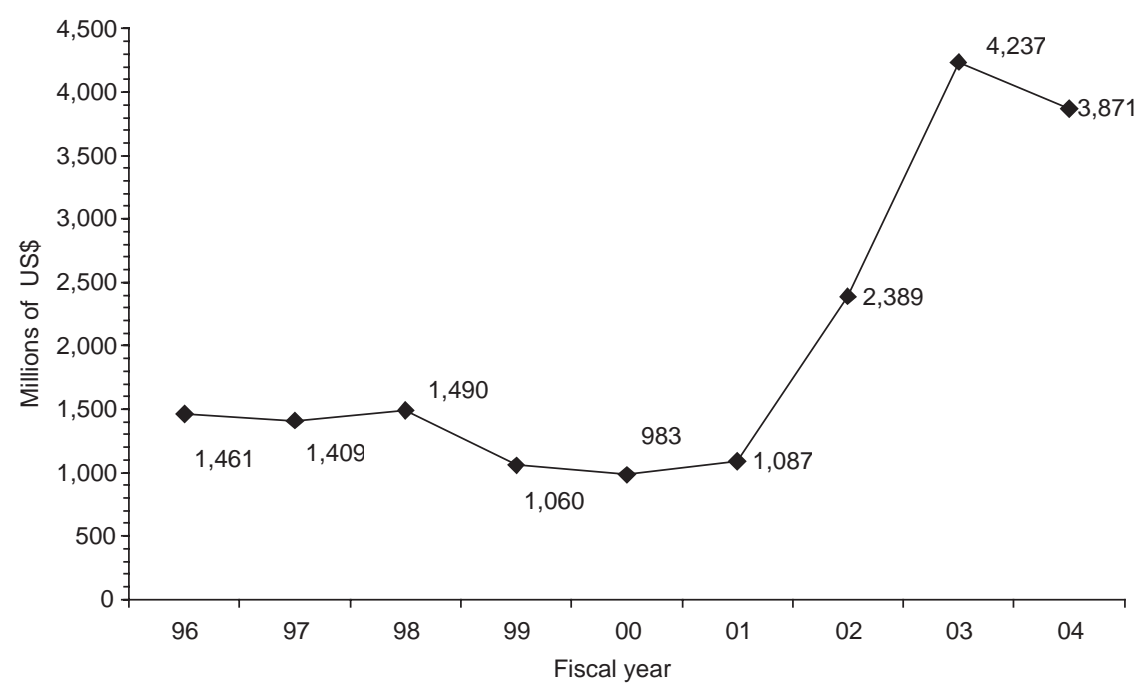


requirements, stimulating all manner of further developments.

\section{The hawaladars' response}

When the crackdown came, only a tiny minority of UK-based hawaladars were prosecuted. Although a significant proportion — but by no means all — of those acting as consolidators were subject to prosecution, virtually all the smaller operators - probably several thousand strong were left unscathed. Moreover, once it became clear that it was the receipt of cash deposits on a wholesale basis which rendered them vulnerable to prosecution, most smaller operators adopted the obvious remedy: instead of passing on the funds collected from retail clients to consolidating hawaladars for conversion into US dollars and onward transmission overseas, as they had done hitherto, they simply opened foreign exchange accounts of their own. To be sure, they consequently lost access to the economies of scale from which the consolidators had hitherto benefited, thereby adding to their costs. But by making some minor adjustments to Customs' satisfaction, they found that they were in a position to recover their business.

One immediate consequence was that the UK-based dimension of hawala networks suffered considerable fragmentation, given that local hawaladars had little alternative but to present themselves as sole operators. Nevertheless, there are now strong indications that commercial logic consolidation is now reasserting itself, although the resultant deficit is now being remedied from overseas. During 2004 and 2005 several leading exchange houses in Dubai — led by Wall Street Exchange and Al-Ansari Exchange, both formally constituted limited liability companies (LLCs) - set up internet-based value transfer systems operating on a global basis. Having done so they have formally signed up local hawaladars operating in the UK and elsewhere as their agents. ${ }^{47}$ If the author understands current developments correctly, the greater part of the consolidating role formerly fulfilled by the now-convicted UK-based consolidated hawaladars has now effectively been repatriated to the major Dubai-based Exchange houses through which global settlements had long been implemented. If so, it follows that UK-based regulators will now have even less access to the financial sinews of the operation than they did when UK-based consolidators played a much more active role in its implementation. Just what impact the recent decision of the Court of Appeal will have on these developments still remains to be seen.

\section{ISSUES FOR REGULATORS}

The growing salience of trust-based IVTS networks - of which the hawala operations discussed in this paper are but one specific example - clearly pose a major challenge to currently conventional regulatory procedures. Given their parsimonious - yet financially and economically rational - approach to record-keeping, IVTS networks do not generate massive, and endlessly duplicated, documentary archives of contractual agreements, delivery notes, receipts and so forth. Hawaladars do of course keep records, and regularly transmit extremely detailed instructions to their partners with respect to issues of implementation. But although this approach makes for high levels of financial efficiency, it represents a major headache for regulators committed to an audit-trail approach, for there is no central registry even in Dubai — in which all these data are stored. In such circumstances constructing an audit trail ceases to be a paper exercise: any attempt to 'follow the money' would have to be implemented quite literally, by visiting the offices of a global network of hawaladars. ${ }^{48}$

In the light of all this, can IVTS networks be brought within some kind of 
meaningful regulatory framework? The author's impression is that very few hawaladars are opposed in principle to the prospect of being subjected to regulation, always provided that such a regime takes adequate cognisance of the logic of their business practices. $^{49}$ If so, the principal obstacle to progress is not so much the hawaladars themselves, but rather construction of a regulatory framework which is fit for purpose. Yet just what should those purposes be? To escape from the blinkers precipitated by narrow post-9/11 concerns, it is useful to begin by going back to basics and reminding ourselves just what it is that the current range of regulatory frameworks are designed to achieve. As far as the author can see, the objectives of such frameworks fall into three broad spheres:

- Fiscal: to constrain individual and corporate efforts to circumvent their liability to pay taxes and duties, and to comply with any other fiscal restrictions which the state might impose.

- Financial: to ensure that the funds lodged with commercial enterprises by retail clients are adequately protected against malfeasance, and that the financial system as a whole remains sufficiently robust to render the probability of system collapse remote.

- Forensic: to prevent criminally acquired funds from circulating within the established financial order.

Of the three, fiscal regulation is the most ancient: taxes, and the necessity to appoint inspectors to monitor concerted efforts by subjects to avoid paying their dues is a phenomenon as old as the state itself. By contrast the emergence of state-sponsored regulation of commercial practices is a much more recent phenomenon, largely precipitated by the failure - especially in Euro-American contexts - of more longestablished trust-based procedures of selfregulation.
By contrast the introduction regulatory initiatives to meet specifically forensic objectives is a much more recent phenomenon. As Naylor puts it:

'Over the last fifteen years there has been a quiet revolution in law enforcement. These days, instead of just closing down rackets, law enforcement goes after the earnings from crime on the theory that confiscating the yield removes both motive (profit) and means (operating capital) to commit further crimes. Therefore a new offence - money laundering - has been added to the statutes of many countries. Tougher reporting requirements have been imposed on financial institutions. And law enforcement agencies now host special units responsible for arresting not malefactors but bank accounts, investment portfolios, houses, cars, even Rolex watches. These initiatives are closely related. Detailed records create a paper trail that aids tracing criminal money, while anti-money laundering laws create new offences to justify its seizure. ${ }^{50}$

Against that background the wave of AML/CFT regulations let loose by the Patriot Act is the culmination of these developments. As Naylor goes on to argue at length, these forensically driven measures are different in kind from their financially and fiscally oriented counterparts: their objective is not so much to maintain integrity of the economic order, but to require agency in the financial services sector to assist the law enforcement authorities by scrutinising each and every transaction passing through their hands for what the regulations proclaim to be telltale signs of money laundering.

While terrorism and drug smuggling are very real problems in the contemporary world — and most especially so in a world where funds of all kinds are routi- 
nely moved around at the click of a mouse - there are now growing concerns that the blunderbuss approach to regulation enshrined in $\mathrm{AML} / \mathrm{CFT}$ is close to being counterproductive. ${ }^{51}$ The collateral costs are proving to be enormous, ${ }^{52}$ but there are few signs that the ultimate targets of the whole exercise are suffering any significant damage, not least because identifying transfers which are actually associated with drug smuggling and the financing of terrorism is a substantially more difficult task than finding a needle in a haystack. This is not to suggest that all efforts to catch such miscreants should be abandoned, and still less to argue that all efforts to improve regulatory procedures in this arena are bound to be nugatory. But it is to insist that a comprehensive reassessment of the utility of current initiatives needs to be made if real — as opposed to symbolic - progress is to be achieved.

\section{Formal and informal procedures compared}

While this is no place from which to embark on such a grand reassessment, it is nevertheless worth presenting a brief review of whether informally constituted value transmission systems are indeed more vulnerable to malfeasance than their more formally organised counterparts, and if so, how those deficiencies might best be remedied. In doing so three distinct sets of questions need to be addressed. First, is it the case - as is widely assumed - that IVTS networks are wholly unprotected against potential malfeasance in all three spheres just identified? Secondly, if self-regulatory measures of a protective sort are in fact available in some or all of these spheres, how does their effectiveness compare with those currently in place in the formal sector? Thirdly, what measures might reasonably be taken to fill the resulting loopholes?

\section{Money smuggling}

On the fiscal front, it is quite clear that IVTS networks can be - and indeed very frequently are — utilised by those who wish to shift value between one financial jurisdiction and another in such a way that the transaction does not come to the attention of the revenue-seeking and/or the exchange control arms of national treasuries. This is not to say that IVTS networks are exclusively utilised by those seeking to circumvent such fiscal controls, since migrant remittances cannot be so classified, but it is undoubtedly the case that some of the outflow from the developed world, and a significant portion of the countertrade from the developing world is composed of transactions of this kind. Nevertheless 'money smuggling' in this sense is in no way uniquely confined to the informal sector. These transfers run alongside and indeed are dwarfed by - the huge volume of footloose funds currently circulated between on- and offshore institutions located within the formally constituted financial sector, ${ }^{53}$ a significant proportion of whose business is concerned with providing their clients with expert advice on how best to minimise their fiscal liabilities. $^{54}$

\section{System security}

Those who insist that there is an urgent need to subject IVTS networks to formal regulation often seek to justify their position by arguing that in the absence of adequate external supervision, retail customers' interests will remain entirely unprotected against malfeasance. Such arguments rest on a lack of awareness of, or failing that a lack of confidence in, the capacity of trustbased coalitions to generate system security. While customers of trust-based systems reap financial benefits from passing their funds through operations whose overhead expenses are very much lower than those which rely on more complex bureaucratic 
procedures, there is little evidence that their funds are significantly endangered by so doing. Despite the huge sums routinely processed through IVTS/hawala networks, complaints of malfeasance are extremely rare. Precisely as Greif's model predicts, given their status as coalition members it is in every hawaladar's personal interest to sustain his reputation for probity vis-à-vis clients and colleagues, and in the coalition's collective interest to take prompt action to exclude any network member whose probity is in any way in doubt.

That said, it is equally clear that such trust-based relationships of reciprocity cannot be universalised. Quite the contrary. They gain their effectiveness precisely because of their deployment within a limited coalition made up of people of similar ethnic origin, who utilise culturally specific understandings and behavioural conventions to underpin their financial dealings. ${ }^{55}$ In the contemporary world the capacity of Euro-Americans to build such coalitions of trust has largely fallen into abeyance: hence, among other things the ever greater salience of formal regulation. However in many other cultural traditions - and most especially those grounded in South and East Asia - the capacity to construct such coalitions is still alive and well. Given the much lower level overheads incurred when such strategies are deployed, it is idle to assume that they are likely to be abandoned with any speed, no matter how much hegemonically conceived EuroAmerican assumptions may lead some observers to assert that such coalitions are by definition no more than criminal conspiracies.

\section{Drugs and terrorism}

Although tax avoidance is in principle just as much a criminal offence as is smuggling drugs and engaging in terrorism, few observers would dispute that offences of the latter kind are infinitely more serious than tax avoidance. With that distinction in mind, the use of the single catch-all term 'money laundering' to cover these very different forms of malfeasance, can only be described as unhelpful. Besides erasing the differing degrees of seriousness in underlying acts of malfeasance, such an elision also obscures a further important difference between the two sets of offences. If the funds transferred in the course of efforts to avoid taxation were legitimately acquired, as is most usually the case, the resultant malfeasance is primarily fiscal in character, and any subsequent prosecution will normally focus on the transfer itself since it is this which leads to removal of the funds from both the purview and the jurisdiction of the revenue authorities. By contrast the AML/CFT regime takes a very different approach, since it is not so much the transfers themselves which are the nominal target, but rather the source from which the funds so transferred were originally derived (as in drug smuggling), or the purposes for which the funds are destined to be deployed (as in terrorism), which render the transactions illegal.

While most of the successful 'money laundering' prosecutions in the USA have focused on breaches of regulatory procedures, the approach deployed in the UK has so far been rather different. Most of the prosecutions launched against hawaladars in the UK have been framed in terms of conspiracy to contravene s. 49(2) of the Drug Trafficking Act, which indicates that:

'A person is guilty of an offence if, knowing or having reasonable grounds to suspect that any property is, or in whole or in part directly or indirectly represents, another person's proceeds of drug trafficking, he -

(a) conceals or disguises that property, or

(b) converts or transfers that property or removes it from the jurisdiction, 
for the purpose of assisting any person to avoid prosecution for a drug trafficking offence.'

In quashing the cases which came before it, the Court of Appeal ruled that in the absence of concrete evidence that identifiable components of the money handled by the hawaladars were indeed the proceeds of drug smuggling, and also the introduction of evidence showing that the hawaladars had access to knowledge that the funds in question were indeed so generated, ${ }^{56}$ their convictions could not stand. But although one line of attack may now be closed, it is still far from clear as to what alternative measures will be pursued. If the UK begins to follow US precedents, hawaladars could well find themselves charged with breaching AML/CFT regulations. Provided that prosecutors managed to escape the necessity to prove anything at all about the origins of the funds in question, they might well have a considerably greater prospect of success.

Yet just how much of a 'success' would such a procedure actually constitute? In a dangerous sleight of hand, a central consequence of such an approach is that financial agencies rather than criminal perpetrators become the central focus of forensic scrutiny. With such a blunderbuss in place, it becomes very easy for the authorities to make dramatic claims about the successful prosecution of the War on Terror and/or Drugs, even if few if any of their highly publicised 'busts' ever enable them to identify, let alone to catch, their ultimate targets. Could it be that all that such an approach yields is the successful prosecution of unfortunate scapegoats?

\section{CONCLUSION}

Despite all these alarms and discursions, the prime focus of this paper has not been on matters of drug smuggling, and still less on terrorist financing. Rather its central con- cern has been with the financial and regulatory challenges thrown up by the everincreasing globalisation of the world economy. With such matters in mind, it should be read as a reminder that globalisation is a two-way process. While recent advances in communications technology may have provided Euro-American enterprises with an opportunity to engage in globalisation 'from above' on an unprecedented scale, those same developments have also provided non-European entrepreneurs with some equally unprecedented opportunities to play the same game in reverse, and on that basis to mount all manner of counterchallenges 'from below'. This paper concerns itself with a specific dimension of these counter-hegemonic processes: those associated with the recent surge in labour migration from the developing to the developed world, and the equally spectacular growth of financial transfers in the reverse direction, such that in many of the poorest parts of the developing world the inflow of value precipitated by migrant remittances now comfortably exceeds that generated by official development aid and foreign direct investment combined. ${ }^{57}$

A salient feature of all such processes of globalisation 'from below' is that they owe little or nothing to international assistance 'from above'. On the contrary, virtually all are intrinsically subversive in two interlinked senses. First, they have emerged as a creative response to the ever more salient forces of Euro-American hegemony, and secondly because the inspiration behind them has invariably been grounded in the creative exploitation of the alterity of their indigenous cultural capital — in other words the resources embedded within the distinctive social, ideological, familial and religious heritage of each such group. This paper highlights one such success story. Having made extensive use of the resources of their kinship networks to create 'escalators' which delivered large numbers of 
migrants of similar origins into specific niches in labour markets throughout the developing world, ${ }^{58}$ specialist entrepreneurs operating from within the midst of the resultant transnational networks have utilised those self-same resources to develop highly effective value transfer systems to deliver their fellow migrants' savings back to the relatively impoverished areas from which they originally departed, no matter how remote their location might be. In terms of grass-roots economic development these initiatives can only be described as exceedingly welcome, even though the efficiency and autonomy with which these networks transfer the resultant liquidity may well be a source of considerable alarm to more formally constituted structures and institutions which regard the prospect of being cut out of a major profit-generating loop as unwelcome in the extreme. ${ }^{59}$

Against this must be set the prospect that these networks could be utilised as convenient vehicles within which to conceal a major downside of globalisation: drugsmuggling and the provision of funds to terrorists. That IVTS networks could be so used is undeniable. There can be no dispute, however, that those with such nefarious purposes in mind could, and regularly do, use the services of formally constituted banks. All that stands in the way is the production of documentary evidence sufficient to satisfy the demands of AML/CFT regulations: few would suggest that that is a serious obstacle to a reasonably well-prepared terrorist or drug smuggler. ${ }^{60}$

By contrast the barriers in the way of entry into hawala networks, no matter how 'informal', appear to be considerably more substantial. Local hawaladars normally serve specific communities, and hence expect to be able to identify their customers on a personal basis without demanding sight of a utility bill. Moreover, when a hawaladar deals with a customer wishing to transfer a very substantial sum (ie in the tens of thousands of pounds) additional considerations come into play. Given his responsibilities as a member of a wider coalition, together with the fact that all his transactions with customers - and especially such a large transaction - are underpinned by a relationship of mutual trust, hawaladars expect (and indeed are expected to) to establish a personal relationship with their customers. In consequence hawaladars invariably expect to establish a personal relationship with such senders, and consequently to gain more than an inkling of the nature of their business activities, before agreeing to despatch a substantial sum on their behalf. To be sure, hawaladars do not normally pass on such information to their partners elsewhere in the network: there is no intrinsic need to transmit such data. By accepting instructions from a customer, hawaladars put their own bona fides vis-à-vis all their other partners in the coalition on the line, and in doing so expose themselves to the prospect of severe sanctions should they put the security of the entire coalition unnecessarily and irresponsibly at risk. ${ }^{61}$

While it would be unwise to assume that this trip-wire will always prove effective, precisely because front-line hawaladars invariably maintain personal relationships with their clients, they are particularly well placed to assist the authorities in their efforts to track down major criminals always provided that the authorities are prepared to accept the essential legitimacy of their financial modus operandi. Given that hawaladars have a built-in interest in keeping their business clean, forensic investigators would surely be much better advised to seek the active cooperation of hawaladars in their efforts to gather intelligence about the likely perpetrators of such unlawful activities, rather than insisting that they produce mountains of indigestible paper, while threatening dire retribution should they not conform to these essen- 
tially bureaucratic requirements. The same might well be true of businesses operating in the formal sector, even if their personal knowledge of their clients may often be of a rather lower order.

In the light of all this, the current use of AML/CFT regulatory procedures as a means - and perhaps even as the principal means - of tracking down drug smugglers and terrorists appears to be seriously mistaken. The result of deflecting attention away from substantive offenders in favour of the financial networks they allegedly utilise has precipitated a wholly predictable outcome: unfortunate scapegoats, distinguished primarily by their alterity, have been found guilty of serious criminal offences, while the real offenders have escaped scot-free. Meanwhile the prospect of criminal investigators gaining the cooperation of network members in their efforts to track down those perpetrators has been actively undermined by their regulatory colleagues' application of a blunderbuss approach. Worse still, the implementation of the new regulatory regime has also added to the burden of overheads carried by the financial services industry, all of which has to be recouped from customers through higher charges. This is precisely the conclusion reached in the Chartered Accountants' report ${ }^{62}$

If it also the case that the poorer and less well-connected one's customers are, the greater the expense of carrying out all the necessary investigations of their backgrounds and purposes will be, it follows that those with fewest resources will have the greatest difficulty in gaining acceptance as clients, and the higher the transaction costs to which they will consequently find themselves exposed. In these circumstances the competitive advantages of IVTS/ hawala networks will be yet further reinforced (always provided they can avoid prosecution for regulatory offences) for all but their most well-heeled and well-con- nected potential clients. Nor will evergreater efforts to impose regulatory conformity be likely to improve matters. Not only are the courts likely to display an increasing tendency to call the bluff of prosecutors, but the incentive to utilise the facilities of informal networks will become steadily greater, if only because of their commercial efficiency; and if that results in IVTS networks moving yet further underground and/or offshore - and there are good reasons to suggest that this has already begun to occur — the forensic objectives of the whole exercise will be yet further undermined.

Last but not least it is also worth remembering that the trust-based financial transfers discussed in this paper are but the tip of a very much larger iceberg. Since the data to which the author has had direct access are far more concerned with outward value transfers from the UK than with the counter-transfers to which the resultant liquidity gives rise, the author has only been able to sketch out the broad outlines of the financial and commercial activities in South and West Asia which the resultant flows of liquidity support. Moreover, given that trust-based networks provide the foundations for a large proportion of financial and commercial activity throughout the non-European world and most especially in communities of Chinese origin - the current scale of funds flowing through IVTS networks of one sort or another is undoubtedly dramatically larger than any of those to which the author referred in the introduction to this paper. This is not evidence of global nonEuropean criminal conspiracy. Rather it should be understood as the financial counterpart of East and South Asia's success in undercutting the high costs of manufacturing activity as currently organised in EuroAmerican contexts. Cost-cutting in the value-transfer market has been achieved by just the same methods: by making intensive 
use of advanced technology, by organising operations on a just-in-time basis, and by cutting out redundant bureaucratic procedures and the extensive use of distributed systems - all pinned together by networks of trust to hold the whole operation together. The result is a product which is frequently superior to, but invariably considerable cheaper than, those that their Euro-American rivals have so far been able to construct. Given all this, the arguments and perspectives which Franco Furger advances in a paper presciently entitled 'Global Markets, New Games, New Rules: The Challenge of International Private Governance', ${ }^{63}$ are of much wider applicability than is currently appreciated.

\section{References}

(1) Fisher, J., Gilsinan, J., Harshman, E., Islam, I. and Yeager, F. (2005) 'Assessing the impact of the USA Patriot Act on the financial services industry', The Journal of Money Laundering Control, Vol. 8, No. 3, pp. 243-252. A report commissioned by the Institute of Chartered Accountants (Yeandle, M., Mainelli, M., Berendt, A. and Healy, B. (2005) 'AntiMoney Laundering Requirements Costs, Benefits and Perceptions', Corporation of London, London, reraches similar conclusions about the high cost and low efficacy of conforming to AML regulations.

(2) An excellent account of the origins of the concept of 'money laundering', and the huge range of financial activities to which it can be and has been applied can be found in Naylor, R.T. (2004) 'The Wages of Crime: Black Markets, Illegal Finance and the Underworld Economy', University of Cornell Press, Ithaca.

(3) A more detailed account of the origins and consequences of the introduction of the Patriot Act can be found in Kochan, N. (2005) 'The Washing Machine: How Money Laundering and Terrorist Financing Soils Us', Thompson, Mason, OH, Chapter 12.
(4) Greif, A. (1989) 'Reputation and coalitions in medieval trade: Evidence on the Maghribi traders', Journal of Economic History, Vol. 49, pp. 857-882.

(5) IMF (2005) 'World Economic Outlook: Globalization and External Imbalances' International Monetary Fund, Washington DC. An extended discussion of the difficulties encountered in calculating the scale of remittance flows on a global scale can be found in Ratha, D. (2005) 'Workers' Remittances: An Important and Stable Source of External Development Finance' in Maimbo, D. and Ratha, D. (eds) (2005) 'Remittances: Development Impact and Future Prospects', World Bank, Washington DC. As a result of growing interest in the subject, estimates are continually being revised upwards. Current estimates suggest that the total flow through formal channels in 2004 was in excess of $\$ 140 \mathrm{bn}$.

(6) This is not to suggest that such operators have access to global delivery networks. Rather they invariably serve a specific community drawn from an equally specific locality, to which their personalised delivery service is consequently restricted.

(7) Although all al-Barakaat's funds were confiscated and the organisation closed down, no formal charges have ever been brought against it, nor has any concrete evidence to substantiate the accusations made against it ever been produced (Naylor, ref. 2 above,. pp. 316ff.).

(8) < http://www.ice.gov/graphics/news/ newsreleases/articles/hawalas052305. htm >

(9) 'U.S. Campaign Produces Few Convictions on Terrorism Charges: Statistics often Count Lesser Crimes', Washington Post, Sunday, 12th June, 2005, p. A01.

(10) Passas, N. (1999) 'Informal Value Transfer Systems and Criminal Organizations: A Study into So-called Underground Banking Networks', Ministry of Justice, The Hague.

(11) Ibid., p. 74.

(12) In addition to Passas's own on-going work, two contributions to the literature 
have been particularly valuable. First, El Qorchi, M., Maimbo, S. and Wilson, J. (2003) 'Informal Funds Transfer Systems: An Analysis of the Informal Hawala System', IMF/World Bank, Washington DC, and secondly, Maimbo, S. (2004) 'The Money Exchange Dealers of Kabul: A Study of the Hawala System in Afghanistan', World Bank, Washington DC.

(13) From what was effectively a standing start in the period before 11th September, 2001, Google now lists over 50,000 pagereferences to hawala. Meanwhile www.moneylaundering.com offers (in exchange for a substantial fee) regular web-based training seminars on Winning the Silent War: Defeating Terrorists and Money Launderers and Behind Enemy Minds: Money Laundering Tactics and Terrorist Schemes. These seminars offer, among other things, accounts of How 'informal value transfer systems' and black market peso exchange laundering methods work. Needless to say, moneylaundering. com relentlessly emphasises the way in which IVTS networks could in principle be used for criminal purposes.

(14) Piore, M. (1979) 'Birds of Passage: Migrant Labour and Industrial Societies', Cambridge University Press, Cambridge. Piore usefully reminds us that no less than 40 per cent of European immigrants to the USA in the period between 1840 and 1914 eventually returned to their countries of origin, taking their savings with them.

(15) Ballard, R. (2004) 'Delivering migrant remittances: The logistical challenge', Journal of Financial Transformation, Vol. 12, pp. 141-153.

(16) McPherson, K. (1993) 'The Indian Ocean: A History of the People and the Sea', Oxford University Press, New Delhi.

(17) Udovitch, A. (1970) 'Partnership and Profit in Medieval Islam', Princeton University Press, Princeton.

(18) Although Muslim merchants soon established themselves as the premier trading group throughout the region, they also faced significant competition from Hindu and Chinese merchants. Both these groups developed parallel means of financing long-distance trade, grounded in each case in their own distinctive cultural assumptions.

(19) The Tamil Chettiars are a classic example of a community of specialist bankers, see Evers, H-D. 'Chettiar Money-lenders in South East Asia', in Lombard, D. and Aubin, J. (2000) 'Asian Merchants and Businessmen in the Indian Ocean and China Sea', Oxford University Press, Delhi.

(20) For the avoidance of doubt it is worth emphasising that although these activities were in a general sense halal (ie they were held to be congruent with the requirements of the shari'a), they were in no sense congruent with, or the ancestors of, contemporary initiatives in so-called 'Islamic Banking'.

(21) In historical terms the hundi appears to be a specifically South Asian contribution to the implementation of value transfer processes, and is now no less widely used in Hindu than in Muslim financial networks. An outline of the current legal status of the hundi as a financial instrument in India can conveniently be accessed at http://www.incometaxindia. gov.in/circulars/1977/Cir221.asp

(22) The volume edited by Lombard and Aubin (see ref. 19 above) contains numerous accounts of the activities of trading networks of this kind.

(23) Greif, ref. 4 above.

(24) Greif, A. (1993) 'Contract enforceability and economic institutions in early trade: The Maghrebi Traders' Coalition', The American Economic Review, Vol. 83, pp. 525-548.

(25) Frank, A. G. (1998) 'ReOrient: Global Economy in the Asian Age', University of California Press, Berkeley.

(26) Hanafi, S. N. (2004) 'Impoverishing a colonial frontier: Cash, credit and debt in nineteenth century Afghanistan', Iranian Studies, Vol. 37, pp. 199-218.

(27) In such peripheral areas hundi-driven hawala systems are still in operation. Monsutti, A. (2004) 'Cooperation, remit- 
tances and kinship amongst the Hazaras', Iranian Studies, Vol. 37, pp. 219-240.

(28) Ballard, ref. 15 above.

(29) This section is the product of more than two decades of ethnographic research into the growth of Anglo-Pakistani transnational networks, during the course of which the author has conducted extensive fieldwork both in Mirpur and in Mirpuri settlements in the UK. While he has published numerous articles on his findings, a summary of those aspects of his research which are most germane to the issues raised in this paper can most conveniently be found in Ballard (2003) 'A case of capital-rich under-development: The paradoxical consequences of successful transnational entrepreneurship from Mirpur', Contributions to Indian Sociology, Vol. 37, pp. 26-58.

(30) Although for heuristic purposes this example is set out in the present tense, aspects of the procedures utilised have changed quite significantly since Customs and Excise introduced a new regulatory framework in 2002. The most salient consequences of these changes are discussed later on. The contents of this section are based partly on discussions with UK-based hawaladars, and above all on careful inspection of their recordkeeping systems as well as their contents.

(31) The author has borrowed the notation for the identification of hawaladars as $\mathrm{H}^{\mathrm{a}}$, $\mathrm{H}^{\mathrm{b}}$, etc from the model set out in El Qorchi et al. (see ref. 12 above). As the subsequent analysis shows, however, hawala deals very rarely take the form of the simple bilateral exchanges which they set forth in their model.

(32) The 'kerb rate' of exchange for the Pakistani rupee - which is effectively the rate offered by local hawaladars — varies according to supply and demand, and in times of crisis can be as much as 10 per cent higher than the official rate. Details of the kerb rate are routinely printed in the financial press.

(33) Detailed accounts of globally oriented hawaladars' brokerage activities are extremely hard to obtain. However, the author has in his possession copies of several major hawaladars' bank accounts, denominated in both sterling and US dollars, recording a significant number of multi-million dollar inter-bank transfers. In his opinion these transfers are best explained as the outcome of just such settlement processes.

(34) Stringham, E. (2003) 'The extra-legal development of securities trading in seventeenth century Amsterdam', Quarterly Review of Economics and Finance, Vol. 43, pp. 321-344.

(35) Neal, L. and Quinn, S. (2001) 'Networks of information, markets and institutions in the rise of London as a financial centre', Financial History Review, Vol. 8, pp. 7-26.

(36) Clay, K. (1997) 'Trade, institutions and credit, contract enforcement on the California coast, 1830-1846', Explorations in Economic History, Vol. 34, pp. 495-521.

(37) Greif, ref. 24 above, p. 544.

(38) The full extent of those flaws is only now coming to the surface. Following a lengthy investigation by West Midlands Police, it has since been confirmed that the 'controlled deliveries' through which Customs had obtained a string of convictions were severely compromised by breaches of due process. On 5th July, 2005, The Guardian reported that following an appeal mounted by five men found guilty of drug smuggling in three such sting operations, Lord Justice Hooper quashed all five convictions because of a failure to disclose vital information about the relationships between Customs and Excise officers, informants and drug suppliers to judges and juries at the appellants' trials.

(39) The Observer, Sunday, 8th July, 2001.

(40) Much of the detailed material in this paper is derived from information to which the author gained access in his role as an expert witness. This material included all the hawaladars' records which Customs and Excise impounded. The expert report which he produced for use in these proceedings can be downloaded from < http://www.art.man.ac. uk/casas/pdfpapers/hawala.pdf $>$ 
(41) Since these cases came to trial, a separate case came before the Court of Appeal in which a statistical expert, Professor Laycock, challenged the validity of Mass Spec Analytical Ltd (MSA)'s methodology, and consequently the validity of the Crown's suggestion that MSA's findings could be used as evidence to support the view that the notes in question must have been used to purchase drugs from the defendants (Benn and Benn [2004] EWCA Crim 2100). Although the appeal was rejected on other grounds, the Court made it quite clear (at para. 44) that 'We accept entirely the evidence of Professor Laycock that these could not properly provide any statistical basis for a conclusion as to the provenance of the suspect notes'.

(42) Given that all hawaladars are in competition with one another for business, and that all consequently play their cards very close to their chests for fear that rivals with better information might well be able to cut them out of the loop with respect to future transactions, the transfer of consolidated consignments of sterling within the UK were regularly conducted through neutral cut-outs. In court, the prosecution insisted that the only reasonable interpretation of such behaviour was as a means of concealing criminal activity.

(43) The Dubai-based brokers with whom the hawaladars had done business sometimes did appear on the charge-sheet.

(44) Ali, Hussain, Khan and Bhatti [2005] EWA Crim 87.

(45) Ballard, ref. 29 above.

(46) The most dramatic example of this was the closure of the al-Barakaat network. See ref. 7.

(47) At present (May 2005) the 'Instant Cash' website of the leading operator in the field lists a total of 85 local agents with whom it deals in the UK. The site also invites further agents to sign up, as do those of all the other major operators. Khanani and Khalia Ltd, based in Karachi, also appears to be operating in the same market.
(48) Paradoxically enough there is one set of archives which could produce an unparalleled insight into the character of global hawala transactions: the bank accounts maintained by all the major Dubai-based Exchange Houses in New York, and through which they appear to implement the vast majority of their global settlements.

(49) Houssein, M. D. (2005) 'Somalia: The Experience of Hawala Receiving Countries', in IMF, 'Regulatory Frameworks in Hawala and other Remittance Systems', International Monetary Fund, Washington DC. Omer, A. and El Koury, G. (2005) 'Regulation and Supervision in a Vacuum: The Story of the Somali Remittance Sector' in Maimbo, D. and Ratha, D. (eds) 'Remittances: Development Inpact and Future Prospects' World Bank, Washington DC.

(50) Naylor, ref. 2 above, pp. 247-248. See also Naylor, R. T. (2003) 'Towards a general theory of profit-driven crimes', British Journal of Criminology, Vol. 43, pp. 81-101.

(51) Fisher et al., ref. 1 above.

(52) Kochan, ref. 3 above.

(53) Robinson, J. (2003) 'The Sink: Terror, Crime and Dirty Money in the Offshore World', Constable, London.

(54) It goes without saying that the line between the (legitimate) minimisation of one's tax liabilities and the (illegitimate) evasion of those liabilities is extremely fine, and its location is largely determined by the firepower of the legal advisers whom one is in a position to engage.

(55) This point is further illustrated in the extended discussion of the role of guanxi in ordering contemporary Chinese business relationships which can be found in Part 5 of Appelbaum, R., Felstiner, W. and Gessner, V. (eds) (2001) 'Rules and Networks: The Legal Culture of Global Business Transactions', Hart, Portland, OR.

(56) In an earlier case (Montila [2004] UKHL 50) the House of Lords confirmed a Court of Appeal ruling that in circumstances such as these 'reasonable grounds 
to suspect' could only be a satisfactory basis for conviction if it was accompanied by knowledge of the actual source of the suspect funds.

(57) Ratha, D. (2005) 'Workers' Remittances: An Important and Stable Source of External Development Finance' in Maimbo, S. and Ratha, D. (eds), 'Remittances: Development Impact and Future Prospects', World Bank, Washington DC.

(58) Ballard, R. (2003) 'The South Asian Presence in Britain and its Transnational Connections', in Singh, H. and Vertovec, S. (eds), 'Culture and Economy in the Indian Diaspora', Routledge, London.

(59) Ballard, R. (2005) 'Remittances and Economic Development in India and Pakistan', in Maimbo, S. and Ratha, D. (eds), ref. 57 above.

(60) The bulk of the funds used by the $9 / 11$ conspirators were despatched to the USA by wire transfer into an account which two of the perpetrators opened at the Suntrust Bank in Venice, Florida. Although the Bank lodged a Special Transaction Report (STR) noting the arrival of these funds, the needle got lost in the haystack. No action was taken. Public Affairs Commission (2004) 'The 9/11 Commission Report', Public Affairs, New York.

(61) Concrete evidence of UK-based hawaladars operating in just this way is available. In one of the 'sting' operations previously mentioned, a participating informer sought to send a large sum of money back to his supplier in Pakistan. Much to his (and Customs') concern, the hawaladar refused to process the transaction, on the grounds that he knew that the depositor was a drug smuggler.

(62) Yeandle et al. ref. 1 above.

(63) In Appelbaum, Felstiner and Gasser (eds.), ref. 55 above. 